\title{
The pedagogy of courage: critical Aboriginal football education in Australia's Northern Territory ${ }^{1}$
}

\author{
Jorge Knijnik ${ }^{2} \&$ Jane Hunter $^{3}$
}

\section{Abstract}

This paper discusses key questions of pedagogical hope and courage through non-formal educational activities such as football. We look beyond standard assumptions of sports as a vehicle to stimulate social cohesion and prevent antisocial and criminal behaviour among Aboriginal youth to address core philosophical and pedagogical questions that underpin sporting promotion within underprivileged communities. During the 2014 FIFA World Cup, eight young Aboriginal top-footballers from the town of Borroloola in Australia's Northern Territory, went to the tournament host country, Brazil, to take part in a range of activities, including spending time with local Indigenous communities. This tour was promoted by the John Moriarty Football initiative. Following the tour, the Aboriginal footballers went back to their community to become sporting leaders and also to continue their football careers. With data gathered from interviews with the central participants of the tour, and by using Freire's concepts of emancipation through dialogic practices, hope, critical consciousness, and untested feasibility, we look at the Borroloola youths' football educational activities as a dialogic space where autonomy and citizenship can be enhanced. Employing the Freirean critical dialogue method, the paper unveils the significant connections between non-formal sporting activities and the flourishing of the pedagogy of courage.

Key Words: Aboriginal youth; football education; pedagogy of courage; pedagogical utopia; critical dialogue; Northern Territory; Paulo Freire; John Moriarty

\section{(c) (1) $\Theta \Theta$}

This work is licensed under the Creative Commons Attribution-NonCommercial-NoDerivatives 4.0 International License.

\footnotetext{
${ }^{1}$ This is a post print version of Knijnik, J. and Hunter, J. (2020). The pedagogy of courage: critical Aboriginal football education in Australia's Northern Territory. Critical Studies in Education For the full version go to https://doi.org/10.1080/17508487.2020.1779768

${ }^{2}$ Centre for Educational Research and Institute for Culture \& Society, Western Sydney University http://orcid.org/0000-0003-2578-8909

${ }^{3}$ School of International Studies \& Education, University of Technology Sydney, http://orcid.org/0000-0001-9232-8895
} 


\section{Introduction}

The rush of life wraps everything.

Life is like this: it warms and cools, tightens and loosens up,

is restful and then restless.

What she wants from us is courage.

(Guimarães Rosa ${ }^{l}$ )

In the late 1950s, a young Australian Aboriginal man played football for prestigious clubs in Adelaide, in the state of South Australia. His football skills were so innovative that he became the first Aboriginal player to be selected to play for the Australian national team in the early $1960 \mathrm{~s}^{2}$. Eventually this man found out that football gave him not only a better economic status but also consciousness of his people's social conditions and a voice to fight for a better social status for Aboriginal people within Australian society.

During this period but on the other side of world, another man was addressing the large literacy gap among underprivileged workers in the Brazilian Northeast. By respecting their cultural traditions and local knowledge, and by using dialogic practices, he achieved amazing outcomes with their literacy progressions within short timeframes. His educational methodologies became known around the world, transforming him into one of the most celebrated educators in contemporary history.

The first man is called John Moriarty, a famous Australian sportsperson who became an activist for Aboriginal rights in his country. The second man is the Brazilian educator Paulo Freire, whose work is a global call to action for critical and democratic education.

Trust. Humility. Love. Critical Consciousness. Hope. Courage. These are some characteristics that connect Freire and Moriarty and are embedded in both men's pedagogical practices and political disruptions. Two men who against the odds continue to inspire the world with their messages of fearlessness: Moriarty, a member of the Australia's Stolen Generation, who was taken from his mother in the small town of Borroloola in the Northern 
Territory (NT) at the age of four, moved between different Australian cities and states, and subsequently grew up in a religious institution; and Freire, who survived hunger in his youth, sought political exile away from his homeland due to his pedagogical ideas, and came to lead one of the most important education revolutions in the past century - which still reverberates throughout the world.

The aim of this paper is to establish a conversation between Freire and Moriarty through football and educational sport activities. Our purpose is to theorize about the potential for the pedagogy of courage to flourish within sports democratic and dialogic spaces. We particularly look at the participants of the 2014 Borroloola Tour (2014 BT) to the Brazil World Cup organized by John Moriarty Football (JMF).

In Australia, scholars have shown that sport has been historically used as a potential way to improve race relations (Hallinan \& Judd, 2009) as well as a means to support the inclusion of Aboriginal people into broader social and community contexts (Adair \& Stronach, 2010). Sport interventions have also been considered by Australian policy-makers as a way to prevent anti-social behaviour among Aboriginal people (Cameron \& MacDougall, 2000). Nevertheless, more critical examinations of the racial and power relationships within the sports arena found historical parallels between North America and Australia; in both countries, the 'myth' of the 'black race' physical superiority, reinforced racism by stereotyping Aboriginal people "in life as sportspeople", a label that risks to disempower them to pursuit other professional aspirations (Godwell, 2000, p. 16). Evans et al (2015) consider that sports have also been used as a panacea to promote the 'cure' for all Aboriginal's issues, from educational outcomes to reconciliation and women's empowerment.

In this paper, we intend to go beyond the standard assumptions of sport as a tool to promote the social good; we also move further from our own previous historical analysis of 
the JMF work in Australia's Northern Territory (Knijnik, Hunter \& Vozzo, 2017). Here, we aim to explore the philosophical and pedagogical backgrounds that underpin educational activities such as football, when it's used as a vehicle to promote social change. We essentially ask whether education-oriented sporting activities can promote autonomous citizens. It's important to test the limits of the questions posed by educators who seek to advance egalitarian civic sport education to empower participants to contest conformist knowledge and established power bases (Luguetti \& Oliver, 2020). Challenging the oppressive social structures and practices within sport settings is the basis of these democratic pedagogies. Drawing upon critical dialogues (Streck, 2014) with key participants of the 2014 BT, we look at the Borroloola youths' footballing educational activities as a dialogic space where autonomy and citizenship can be enhanced (McInerney, 2009; Formosinho, Jesus, \& Reis, 2019).

The paper starts with a thick discussion of Freire's ideas. We expand the notion of the 'oppressed' from the ones who are at the bottom of the social scale to the ones who, given their cultural or territorial displacement, have lost their cultural references and become invisible (Freire 2000; 2016). Next, we provide a brief historical account of John Moriarty’s trajectory within Australian sports to show the paradoxes and enduring racism faced by Australian Aboriginal sport people. We then discuss our research journey that allowed us to unveil the stories of the 2014 BT that we present and discuss in the ensuing sections. Our participants' stories demonstrate that beyond discourses of improving behaviour and educational outcomes, football as an educational activity can promote hope when participants are embodied with the necessary courage to embrace it. Finally, we propose an actual pedagogy of courage across sport education programs. 


\section{Freire: Voice and hope to the displaced}

In the early 1960s, Freire started to instruct illiterate mature sugarcane labourers who endured extreme scarcity in Brazil's Northeast. His purpose was to liberate their voices to generate words within their actual social contexts. From there he realized that there is no solution for the liberation of the oppressed unless their teaching is embedded in activities that are "rooted in concrete situations" of oppression (Freire, 2000, p. 37). Having a voice and words to name the world is the first stage of the process of conscientização, that will lead to the enhancement of the critical consciousness required by the oppressed to stand up against the tyrannical components of their lives (Freire, 2000).

Many interpreters of Freire's work believe that when speaking about the oppressed he only talked about people at the bottom of the social ladder. This could not be further from the truth. Freire in fact tells us that people who have been colonized and/or displaced are the oppressed in current societies (Freire, 2000). Colonized people have lost their voices, which have been replaced by the colonizer's ideas. They struggle to find their original voice and thoughts. With their voices lost, their words and language are not valued in their new cultural environment. They enter into a process of self-depreciation, because as either colonized or displaced human beings they

[do not] realize that they, too, 'know things' they have learned in their relations with the world and with other women and men. Given the circumstances which have produced their duality, it is only natural that they distrust themselves. (Freire, 2000, p. 53)

Helping the oppressed to name the world is a foundational step to dismantling this distorted vision they may have of themselves (Freire, 2004). By valuing their own prior life experiences and cultural knowledge, Freire wanted to develop autonomous citizens who were accountable for their own education (Freire, 1996). He raised his voice against the banking 
model of education that not only considers students to be "empty vessels", but also controls their thinking and inhibits creative power (Freire, 2016).

One of Freire's most relevant early field experiences with adult literacy occurred in 1963 in the impoverished village of Angicos, in the Northeast state of Rio Grande do Norte. Freire's group spent a year carefully planning their Angicos educational (Silva \& Sampaio, 2015). Angicos has deeply influenced Freire's future political-pedagogical practice, as it was there that he realized education's social transformation potential (Gadotti, 2014). Angicos gave him evidence that literacy is better achieved when participants' realities were embedded in their literacy process (Gadotti, 2014). The Angicos' boia-frias ${ }^{3}$ were learning to read their world. Francisca de França Germano, one among 300 community participants said that, before the classes, "I didn't know what people was; I learnt at Paulo Freire's school” (Silva \& Sampaio, 2015). Germano's testimony shows that Freire's dialogical practices were able to establish dialogues with the most genuine part of each person, letting them learn that there are names for things such 'education', 'poverty', 'oppression', and that these things are interrelated (Torres, 2001).

Angicos' participants were regaining their voices and self-esteem; it was the beginning of the process of conscientização, which starts when people and communities look past daily events to realize that the social restrictions blocking their growth are challenges rather than hurdles. These are what Freire calls "limit-situations" (Freire, 2000, p. 100).

With voice regained - not as a gift but as community triumph - in the foundational steps of naming the world, learners are ready to move into the next phase of their conscientização to enhance their liberation as community members. Here the political facet of Freire's pedagogical philosophy emerges more strongly. Known as sharing the world, this second step is when learners and teachers begin to deploy the knowledge they have with the new words they now enjoy owning (Freire, 2000; Streck, 2014). It is a dialogic process aimed 
at restoring the humanity of oppressed individuals and their communities. This is the moment when the culture of silence and fear starts to break down the language of community; it is only then that hope becomes a real possibility (Freire, 2000, 2004).

Hope is what happens when communities, facing the limiting situations of oppression, start to plan limit-acts (Freire, 2000) that will push them to overcome their subjugation. This is how the once voiceless and displaced navigate the conscientização process. Through prophetic thought they envisage their freedom, their utopia, a world of opportunities that goes beyond denouncing oppression. It is what Freire calls the untested feasibility: a future that will emerge by the changes we do in the current conditions of oppression; it is a potential that transcends the border of the present 'limit-situation' (Shor \& Freire, 1987).

The pedagogies involved in the process of conscientização are vital to the politics needed in the preparation of critical agents who will imagine the future (Giroux, 2011). Dialogue, not as a tool but as a method, is key to these critical political pedagogies (Streck, 2014; Knijnik \& Luguetti, 2020). Dialogue promotes visibility to otherwise subaltern stories and racial discriminations. Critical dialogue as a project stresses the need of communities to actively change and produce knowledge. It supports communities by giving them abilities and most of all the courage to contest everyday conventions (Giroux, 2010, 2011; Means, 2014).

In the next section we demonstrate how notions of hope and courage were embedded into the life of John Moriarty and the 2014 BT.

\section{Moriarty: racism, football, consciousness - and the 2014 Borroloola Tour}

Nobody can summarize 60,000 years of habitation, or more than 200 hundred years of white occupation in one section of a paper. While recent acknowledgement of the significant impact of Aboriginal culture over millennia and the official apology delivered by the Australian 
government for the suffering imposed on the Stolen Generations are steps towards reparation (Rudd, 2008), white Australia has yet to fully compensate its Aboriginal people for the violence and the social disadvantage caused by the European invasion (Read, 1982).

Aboriginal people have been participating in the Australian sports scene over many years (Maynard, 2009), whilst facing an enduring obstacle: racism (Tatz, 1987). The ongoing bigotry that still exists in the country's mainstream sports towards top Aboriginal athletes cannot be hidden behind cultural celebration programs such as the 'Aboriginal Rounds' in the National Rugby League (NRL) and the Australian Football League (AFL). The continuous vilification of the Aboriginal AFL star Adam Goodes as recently as 2015 is evidence that neither the success of Aboriginal athletes such as the high-profile Olympian Cathy Freeman has ceased discrimination in Australia's sporting milieu (Matamoros-Fernandez, 2017).

However, even when covert or openly racist, sporting activities have also provided numerous Aboriginal people with an outlet where they can share distinct values and personal stories with the broader Australian society and its multicultural communities (Burdsey \& Gorman 2015). Sporting achievements have meant cultural belonging and social empowerment for some Aboriginal communities (Bond, Phillips, \& Osmond 2015; Stronach, Maxwell, \& Taylor 2016). This was the case for John Moriarty.

After being taken forcibly (often this is termed 'stolen') from his family in the Northern Territory when he was just four years old, Moriarty was sent to a small New South Wales (NSW) town in the Blue Mountains where he lived until the age of 12 years. Then, as public pressure started to mount over 'stolen Indigenous children', he was moved to the Anglican Church dormitory in Adelaide with other Aboriginal boys, including the wellknown Aboriginal activist Charles Perkins (Moriarty, 2000). Playing sports was the main distraction for this group of boys, who quickly caught the attention of local football coaches for their physical and sporting prowess. In the late 1950s, Moriarty was already a star player 
of Juventus, the Italian community club in Adelaide. His newfound football stardom brought him social and economic status, as well as a sense of acceptance that was not the norm for most Aboriginal people at that time (Knijnik et al, 2017).

Moriarty quickly became known as one of the best football forwards in South Australia, and he was constantly called to represent state and national teams. Travelling and playing national and international football broadened Moriarty's view of the world. However, his sense of acceptance within the football community was cut short when he found out that his club and the state football authorities had to gain approval from the South Australian Protector of Aborigines so that he and the other Aboriginal footballers could leave to play outside the local jurisdiction (Maynard, 2009). This social context elevated Moriarty's social consciousness about Aboriginal people's oppression in Australia, and he later became an activist for Aboriginal rights (Moriarty, 2000).

Moriarty's roots connected him to Borroloola, a small rural town in the Northern Territory (NT). This connection to country together with his football history led him to create the first JMF football program in Borroloola, which was designed to give Aboriginal young people from that village involvement in sport and opportunities to look at a possible life beyond their small town (Knijnik et al, 2017).

It was with this idea in mind that JMF planned the 2014 Borroloola Tour to the World Cup. They considered that travelling to Brazil and enjoying the atmosphere of this "great football country" (Moriarty, in Knijnik et al, 2017) would be a powerful and inspirational activity that may in turn expand the JMF participants' conscientização. It was their hope that the football and all that surrounded the experience would be a powerful means for developing autonomous children (Freire, 1996). And finally, a delegation of adolescent players, adult coaches and program managers from Borroloola went to the 2014 FIFA World Cup. 


\section{Our research journey to the Borroloola's voices and football stories: a critical dialogue}

In Freire, critical dialogue is a method to unveil the realities that people live in (Streck, 2014). Critical dialogue is a tool to help people read the world-not only the word. The Freirean dialogue is not a psychological intervention; it's a critical instrument to interpret the world (Knijnik \& Luguetti, 2020) in order to change it (Freire, 2004; 2016). In Freire, critical dialogue is a political instrument (Streck, 2014).

A critical dialogue has inspired this paper's authors to come together to conduct the research. The first author is a Brazilian teacher, former football coach, academic and social activist who has lived four decades in different regions of Brazil, including in close interactions with first nation's peoples in Brazilian northeast, before migrating to Australia. He combines a broad view of the 2014 World Cup social, educational and political impact on his home country (Knijnik, 2018) with an extensive knowledge of football tactical details (Knijnik, 2014). His familiarity of Brazil's geography and history, associated with his acute perspectives on the 2014 mega event placed himself in a unique position (Pang, 2018) to establish a rapport with the study participants, particularly with the youth, with whom he exchanged some words in Portuguese that they learned while in Brazil. Furthermore, like most Brazilian educators concerned with social justice, he has Freire as his politicalpedagogical and philosophical guide (Knijnik, 2020).

The second author is also an activist and teacher who for the past three decades has taught, researched and worked in Australian policy spaces championing public education as a means to decrease disadvantage for young people in schools (Hunter, 2015). She has supported Indigenous emancipation in her work in schools including advocating full Australian citizenship (Hunter \& Jimenez, 1999). Her long-established friendship with John Moriarty's 
family helped the authors to approach the foundation known as John Moriarty Football (JMF) who facilitated contact with the study participants, namely: John Moriarty himself; Elvis, a 40-year old white man of Croatian background, with significant experience of football training and education (then JMF football manager and 2014 BT leader); and four young participants of the $2014 \mathrm{BT}$, aged 14 to 16 (two girls and two boys).

The authors cannot consider themselves as 'insiders' of the JMF community in that they promoted the BT excursion. Hence, the next step in the study design was to establish a series of ethical protocols ${ }^{4}$ that supported the research aim of critically analysing the social meanings of the 2014 BT. These protocols included a research information package and consent letters to all adult and young participants. In the case of the players there was initial mediation by the local JMF educator.

With the Aboriginal youth, the study design involved respectful conversations about the best time of day to collect interview data and trust-building ideas of how to approach talking with the players. Their interviews took place in the Borroloola JMF headquarters in the NT and were conducted via videoconference in the presence of two JMF educators. Their company helped to focus the responses, and it reassured the players in being able to talk freely. There were moments when the JMF educators prompted the players for more detail about a particular story that otherwise would not have been fully disclosed. Each time the researchers introduced themselves to the players they reiterated genuine interest in their stories, highlighting the importance of their participation in the two-way dialogue.

The researchers met face to face with Elvis in a club in South Western Sydney and with John Moriarty at his office in Northern Sydney. All these conversations helped us in establishing critical dialogues that enabled examination of Freire's concepts against the background of the 2014 BT participants' football lived experiences. The conversations permitted further extension of Freire's concepts of hope and education, and its role in the 
critical pedagogy of courage in football. What follows are the accounts of Moriarty, Elvis and the struggle of young people for freedom and agency, and their stories of hope and courage.

\section{Freedom}

The 2014 BT provided these Aboriginal young people with moments of joy ("doing the Mexican wave on the stands!”), frenzy ("being cheered by 3,000 Brazilian youth while training with the Socceroos in their Vitoria city camp") and happiness ("meeting the Socceroos football idols such as Tim Cahill”). According to them, few experiences could compare to the freedom they felt while swimming in a river that had no crocodiles, unlike the Borroloola rivers. This happened when they visited an Indigenous community in the Brazilian state of Mato Grosso. For these young people, this activity alone was quite a unique event. It is also a metaphor for the holistic freedom brought to participants by JMF programs - not only for their bodies but also for their minds. As they engaged in various relationships within the world of football, they expanded their understandings of cultural realities and how these vary in different social contexts (Freire, 2016).

The freedom that infused JMF programs was well represented in the views of its manager, Elvis, on the state-of-the-art of football training in Australia. Elvis was critical of some aspects of the training and development of players:

It's very textbook-oriented especially with the Federation curriculum coming into play. I think a lot of talented players get stifled and are very robotic and that's why we don't have a creative midfielder to a degree. You have to give those gifted players a bit of freedom.

Elvis expressed core elements of Freire's pedagogy and the notion of the "empty vessel". Moreover, he applies this idea to football training. An important Freirean lesson concerns the imperative for educators to respect the knowledge of their learners, which is built within and 
through community practices. According to Freire (1996), the act of teaching only exists because initially human beings learned through social interactions. Hence, from a Freirean perspective there is no real learning if teachers do not respect their learners' understandings of the world and their creative bodies and minds that act upon this world. When Elvis refers to "robotic" players this is exactly what he stands against. He firmly believes that you "have to let people be themselves as well as to get the best out of them". This requires a commitment to the promotion of the critical consciousness of the learner, not from the teacher's perspective, but by posing problems young people need to solve by themselves in order to develop their own viewpoint (Freire, 1996, 2016). Therefore, football training for Elvis is not a range of mechanical repetitions that players need to execute till they reach 'perfection'; instead, it's an opportunity for young people to engage in a series of games that, in Elvis's words, "promote their own decision-making out there".

Elvis's vision of the educational process of football reflects Freire's (2000) beliefs on what education should be in the largest sense: a political project of freedom (Giroux, 2010b). This view parallels John Moriarty's. Moriarty explained that they train their staff on a regular basis and have "people like Craig Foster" showing them what to do on the ground and with training equipment such as cones, modified balls ... dribbling, touches, connections, thinking ahead". During this exchange, he paused, reflected and then continued:

But very much loving the game with their [the Borroloola young people] touches and their skills and developing their way because most of the time they play in bare feet and we [in the Anglican church where Moriarty was raised] did it too. Those sort of things you can learn. To use your body in a different way but in a natural way. So you're trying to maintain that connection with who they are.

It was at this moment that Moriarty touched on the notion of Aboriginal people being 'naturally gifted athletes'. He claimed football as the ideal vehicle to: 
ramp up the capabilities of these people, because I feel that Aboriginal kids are tailor-made for the sport. They have dexterity for football, quickness, eye-hand coordination, the lot. Quick on their feet.

This claim was supported by Elvis, who said, "The untapped talent is with the Indigenous, they are just natural talent' and coaches need to 'hone that'".

The myth of the 'instinctive and native Aboriginal athlete' is widely critiqued in the Aboriginal studies literature (Apoifis, Marlin, \& Bennie, 2018; Hallinan \& Judd, 2007). Knijnik et al (2017) point out that this notion is a "fairy tale" that does not acknowledge either the historical challenges of these populations or their perseverance in order to overcome the socio-economic and cultural obstacles to achieve sport success and stardom. Despite general agreement with these critiques of the "natural savage sportsperson legend", Aboriginal sports programs cannot be sustained by their athletes" "natural talent" alone and need support and funding from official agencies and sponsors.

When analysed through Freirean lenses, the words of John Moriarty and Elvis assume a different meaning that is crucial for understanding the kinds of freedom promoted by the JMF programs. What they praise, is not the freedom of the young people, but their capacity, together with JMF educators, to break the "rigid disciplinary boundaries and the cult of expertise" (Giroux 2010b, p. 187) of professional coaches and a standardized curriculum that does not see young people as much more than 'playing machines' that lack the wisdom and freedom to make personal decisions on the field or in their own lives. Therefore, this praise is perceived as contrary to football marketing principles that often want to domesticate everything about a player; instead, JMF wants to set up their young people as free agents who can control their own destiny (Darder, 2017; Freire, 2004).

\section{Social agency}

In our critical dialogues with the 2014 BT players, they explained how good it was for them 
to be in Brazil and "make a lot of new friends". For one of the female players the best part of the 2014 BT was "going out to the community, meeting the local people, making new friends who showed us their culture". Building this intercultural dialogue was part of a broader educational process that did not stop in the classroom but went beyond it to promote the idea of critical social agents (Freire, 2016). They acknowledged that the relationships the players established during the tour made them feel stronger as a group; in addition, their interactions with local Brazilian Indigenous communities also helped their hosts to strengthen their cultural agency: “The [Indigenous] Brazilians are losing some of their culture, so they continued their culture by showing it to us."

The 2014 BT also empowered the players when they returned to their community: "Our family put up a welcome banner and gave us a welcome home party; that was the first time this has happened in Borroloola." They came back to their community keen to share what they learned from the tour, to show the community their cultural exchanges with the 'others' and that they were ready to become historical subjects - not controlled anymore by external forces - in their remote communities (Freire, 1996).

A significant role that the 2014 BT players undertook was one of representation. As John Moriarty said, "Not only was it the game from Borroloola but from their family and community - the tribal [Yanyuwa] group they came from.” As agents of their own people and culture, these young people were taking up social responsibilities. Hence, they became more 'autonomous citizens' in their daily dealings with the world outside Borroloola. John Moriarty recalled that once the process began, "our kids were provided with uniforms, the JMF gear, and once they put that on it transformed them - they are part of a team, and that's special." The uniforms they used in their travels made them feel the responsibility of being 'ambassadors' of their communities; this sense of leadership provided a growing sense of social agency (Freire, 1996). They were now representing their NT communities in Brazil. 
There was a moment in the 2014 BT where John Moriarty saw the rise of social agency among the players. This occurred after they left the Socceroos camp in Vitoria city. Here, the group went to watch the Australian National Team playing in Cuiabá against Chile. Due to issues with his yellow fever vaccines John Moriarty could not go to the game, but he met them afterwards in Rio de Janeiro. He immediately detected a sense of collective selftransformation (Aronowitz, 2015) in the whole group:

Those kids were so taken. They were there part of a huge crowd. You could see the differences when I met them in Rio after that game. They had changed significantly, quieter, seeing that they could be part of a system that could be quite challenging for them but that could also provide an elevation for them in the future for their game and whatever aspirations they may want to have.

Throughout his interview Elvis too highlighted the relevance of the collective transformation for the players and how this was reflected in their game. The collective sense of social agency is embedded in Freire's work. Freire $(2000,2016)$ advocated for education that does not focus on individual achievements nor the social mobility of top-ranked students. Rather, he disseminated the idea that every education that calls itself democratic, needs to emphasize the collective self-transformation of its students as the most desired outcome.

\section{Critical hope}

A topic that permeated all conversations with the 2014 BT participants was hope. Not hope as an ethereal feeling, but in the Freirean sense of critical hope with the possibility of change: the idea of self-determination but also the obligation for individuals to create their own life options and decide their own destinies (Freire, 1996, 2004).

Elvis viewed his role as a sports educator who was responsible for the development of young people in Borroloola: "My priority is to make sure things get developed, the young people, the program, everything. That's why I do this. I am doing something that I love.” As 
he detailed his professional activities, it was clear that many of them went beyond football, including trying to engage the parents of these young people in their child's sporting life with barbeques and breakfasts. He concluded the interview with a major claim of hope: "We're trying to broaden their horizons in any way that we can, to encourage them to go onto bigger and better things." Hence, for Elvis, the 2014 BT was a chance to promote not only individual development but also community aspirations (Freire, 2016) and social responsibility (Giroux, 2010a). Elvis added: “The younger children at school look at the ones who travelled and think they might have that experience one day too."

Hope is also apparent in John Moriarty's words when he talks about the JMF programs. He believes that football can be a "real anchor" for young people at Borroloola. He claims that while they have to be able to find a good job and get a good education, they also have to

have that vision, that love of where you want to go, how you want to do things and how you connect with life and how you've led yourself and your family for a path forward.

John Moriarty pointed out that the JMF programs go beyond the sports side; they include literacy, good diet and health education and other themes to equip young people to "strive for whatever ambitions they would have to get on in their life in Australia." By looking at football as a pathway to educate Borroloola young people in this way, he echoes Giroux (2010b), who argued that children should be educated to become "critical citizens rather than potential employees of Walmart” (p. 185). Through limit actions, John Moriarty envisages and builds the "untested feasibility" (Freire, 2000, p. 65) for these Northern Territory communities, as he seeks to create pathways where "[young people] can see beyond their little community and have opportunities and develop opportunities similar to what I've had" . 
These players also proclaimed their sense of hope as one of the greatest outcomes of the 2014 BT. They understood that, instead of being fixed in their remote community, the football tour gave them the opportunity to see the world not as a static reality but as "a reality in the process of transformation" (Freire 2000, p.71). This tour built the hope of becoming (Freire, 1996). The players took to the world and now they aspire to be "a better coach, to take other teams out, to coach a new generation". One of the female players said, "I want to keep going and further my career in football and perhaps be a coach for the Socceroos or the Matildas ${ }^{6 “ ;}$ a male player added, "I want to further my educational career."

It is relevant to point out that more than seeking to fulfil each child's human "potential", the educational process they went through as part of the 2014 BT pursued the notion of human transcendence; it connected knowledge, power and action (Aronowitz 2015). In this sense, Freire's (2000) humanist philosophy and JMF's educational programs have the same aim: rather than being generous paternalist acts, they are instruments of community liberation.

\section{Courage}

Towards the end of his interview, John Moriarty spoke about his days as an Aboriginal young person. Suddenly, he lifted his shirt, pointed to his abdomen, laughed and asked: "See that scar?" He told us that when he was very young he had to practise with spears:

Learn to make them and throw them at each other. You'd have to have a number of spears in your hand, someone throws them at you then you flick the spear on so they have to aim it at you. We had to do that when we were young. Of course, with small ones you have small spears but you had big ones with the men so...

This story surprised us. We were rendered speechless, but he quickly added that the spears points were rounded: "I wouldn't be here because you can see a spear mark right there" and 
he again showed the wound on his torso. Finally, he shared, "Throwing the spears was like a sport but also like training to cope with life. You have got to have courage."

This was the ongoing and critical lesson young people developed during their time in the JMF programs and in the $2014 \mathrm{BT}$; it was about courage. Courage to move forward towards the untested feasibility (Shor \& Freire, 1987) they envisage during the JMF programs. Courage to plan a future that will only be viable if education expands the students' chances of entering into relationships that enable them to critically engage with diverse people and analyse potential ways of living (Freire, 2000; Giroux, 2011). If young people are to understand their present and to shape their future, it is important that education provides them with lifetime instruments that allow them to read "the world critically" (Giroux, 2010b, p. 192).

John Moriarty stressed that this ability for participants to critically read the world and the word (Freire, 2000) and to courageously move beyond their "little bush town in the Northern Territory" is what the JMF programs aim to provide:

What we want to do is make sure, with our football, is to show there are a lot of other elements in life that they have to overcome and there will be many challenges of course, but at least they can see that there is a pathway there and with our coaches saying 'You could do this', 'Would you like to do that?' and just keep all those visions in their minds.

During the course of our interview with the 2014 BT players, they referred a few times to how they were "scared about being in another country" or to "how creepy it was to be halfway around the world, two days travelling on a plane". One male player said that playing football on the Brazilian beach was "hard, compared with the Australian soil. It hurt my calf muscles". At the same time, they felt proud of themselves for having coped with their fears. Making and maintaining relationships with people from other cultures were also a priority for the 2014 BT players. One said, "To overcome the language barrier we had to use 
our hands a lot to communicate." A female player said that since returning to Australia "we try to keep in touch via Facebook". This social upskilling was an important step to growing the cultural capital of these young people and the whole JMF program. This leads to the central aim of humanistic education as seen by scholars like Freire (2000): to be able to critically understand new realities and compare those with your own towards an ongoing humanization of every human being.

For Elvis, just the fact that they were "getting out of Borroloola" already demanded a great deal of courage. This was not a regular teenagers' excursion with their school. The group struggled to get funding. Elvis recalled that they wanted to bring 12 young people but one major funder pulled out just a few months before the trip. He revealed that there were conversations about "pulling the plug" on the trip, but he thought this was an opportunity that they could not miss and they mustered inner resources and courage in the face of the challenging probabilities (Gallos, 1997) and went ahead with their plans. Elvis and the JMF leadership team showed the courage and a passion needed to move ahead with the excursion plans:

It was very hard to getting it all together because a lot of these kids didn't have any paperwork, birth certificates, etc. We had to travel to Darwin [NT capital city] which is 12 hours from Borroloola a few times to get paperwork done.

As Elvis detailed the many obstacles to getting 2014 BT to Brazil and the courageous ways JMF dealt with them, he revealed how human lives are conditioned by social factors, not determined by them (Freire, 2000; 1996), and that intervening in the social order to change it is a duty of cognizant citizens (Giroux, 2011). He said that by doing "business as unusual" 2014 BT at last had "that nice feeling of finally getting on the plane". 


\section{Pedagogy of courage, sports education and Aboriginal people}

The success of the 2014 BT was a major outcome for JMF that took a lot of planning and goodwill to become a reality. However, this tour is far from being the only possible result from a program that provides educational and sporting activities to children and young people living in remote Australian communities.

In this paper we have connected the prophetic understandings of Freire to John Moriarty's actions to achieve an untested feasibility and bring young people from his hometown of Borroloola to the other side of the world. It is a story of Moriarty and his colleague Elvis, two people who promote freedom and critical citizenship within their communities and beyond. Through a narrative that encompasses hope and courage, and also dialogic practices that give voice to the displaced and the colonized, this paper illustrates how sporting activities can stimulate social agency, freedom and hope. All of these elements were present in the everyday educational actions of JMF staff; we argue that they have modelled a powerful pathway towards a pedagogy of courage.

The pedagogy of courage crafted here considers the future as a problematic, an unsolved possibility that requires individual conscientização if it is to mobilize communities to change their futures instead of accepting the inexorable oppression from social and hierarchized structures. Such structures are also usually present within sporting programs, even though many times coaches and sponsors try to reduce these programs to mere places of consumerism of already-set technologies and techniques. The pedagogy of courage within sport breaks with this marketing logic to support the development of social agency and freedom. It gives hope to the displaced. The pedagogy of courage uses passion and creativity to help individuals and communities strive for opportunities and imagined destinies that may 
initially appear to be beyond their reach - a future, as Freire might say, that has yet to be conceived.

More than a set of correct steps that may end up modelling a new pedagogical toolkit to football training, particularly with displaced Aboriginal communities in Australia, the pedagogy of courage is infused by a humanistic philosophy that aims to liberate individuals and social groups. In order to embed their programs with the pedagogy of courage, educators must look beyond the walls of objective and quantifiable outcomes of traditional sports education programs to put in place acceptance, love and dialogic practices that will enhance participants' voices and agency.

The pedagogy of courage can be then measured when participants realize that their everyday sporting activities can lead to 'dreamed' and 'yet to be' results; when they comprehend that they have to fight for freedom at every stage of their lives. And also when young people have the courage to understand that, as one Aboriginal male player stated: "This was the experience of a lifetime but it won't be the last." These words demonstrate the outcome of a pedagogy that instils in young people the necessity to desire and to design their own life pathways - and not be directed by external forces. While not being - and not aiming to be - an educational panacea, the pedagogy of courage aspires to teach that better life experiences are yet to come, and young people can learn to pursue opportunities as they unfold every step of the way. As both Freire and Moriarty say, they can dare "to be more".

\section{References}

Adair, D., \& Stronach, M. (2010). Natural born athletes? Australian Aboriginal people and the double-edged lure of professional sport. In J. Long \& K. Spracklen_(Eds.), Sport and challenges to racism (pp. 117-134). London: Palgrave MacMillan.

Apoifis, N., Marlin, D., \& Bennie, A. (2018). Noble athlete, savage coach: How racialised representations of Aboriginal athletes impede professional sport coaching opportunities for Aboriginal Australians. International Review for the Sociology of Sport, 53(7), 854-868. 
Aronowitz, S. (2015). Against schooling: For an education that matters. London: Routledge. Bond, C., Phillips, M., \& Osmond, G. (2015). Crossing lines: Sport history, transformative narratives, and Aboriginal Australia. The International Journal of the History of Sport, 32(13), 1531-1545.

Burdsey, D., \& Gorman, S. (2015). When Adam met Rio: Conversations on racism, antiracism and multiculturalism in the Australian Football League and English Premier League. Sport in Society, 18(5), 577-587.

Cameron, M., \& MacDougall, C. J. (2000). Crime prevention through sport and physical activity. Canberra, ACT: Australian Institute of Criminology. Retrieved from https://aic.gov.au/publications/tandi/tandi165

Darder, A. (2017). Reinventing Paulo Freire: A pedagogy of love. New York: Routledge.

Evans, J. R., Wilson, R., Dalton, B., \& Georgakis, S. (2015). Indigenous participation in Australian Sport: The perils of the 'Panacea' proposition. Cosmopolitan Civil Societies: An Interdisciplinary Journal, 7(1), 53-79

Formosinho, M., Jesus, P., \& Reis, C. (2019). Emancipatory and critical language education: A plea for translingual possible selves and worlds. Critical Studies in Education, 60(2), 168-186.

Freire, P. (1996). Pedagogia da autonomia: Saberes necessários a prática educativa [Pedagogy of Freedom: Ethics, democracy and civic courage]. São Paulo: Paz e Terra.

Freire, P. (2000). Pedagogy of the oppressed ( $30^{\text {th }}$ Anniversary edition). London: Continuum.

Freire, P. (2004). Pedagogy of hope: Reliving Pedagogy of the Oppressed. London: Continuum.

Freire, P. (2016). Education for critical consciousness. London: Bloomsbury Publishing.

Gadotti, M. (2014). Alfabetizar e Politizar. Angicos, 50 anos depois. Foro de Educación, 12 (16), 51-70.

Gallos, J. V. (1997). On creating leaders: A pedagogy of courage and passion. Journal of Management Education, 21(1), 6-8.

Giroux, H. (2010a). Lessons from Paulo Freire. The Chronicle of Higher Education, 57(9), B15-B16.

Giroux, H. (2010b). Bare pedagogy and the scourge of neoliberalism: Rethinking higher education as a democratic public sphere. The Educational Forum, 74(3), 184-196.

Giroux, H. (2011). On critical pedagogy: USA: Bloomsbury Publishing.

Godwell, D. (2000). Playing the Game: Is sport as good for race relations as we'd like to think? Australian Aboriginal Studies, Issue 1/2, 12-19.

Hallinan, C., \& Judd, B. (2009). Race relations, Indigenous Australia and the social impact of professional Australian football. Sport in Society, 12(9), 1220-1235.

Hallinan, C., \& Judd, B. (2007). 'Blackfellas' basketball: Aboriginal identity and AngloAustralian race relations in regional basketball. Sociology of Sport Journal, 24(4), 421-436.

Hunter, J. (2015). Technology integration and High Possibility Classrooms: Building from TPACK. New York: Routledge.

Hunter, J., \& Jimenez, S. (1999). Civics and citizenship education: What pedagogy? What possibilities? Curriculum Perspectives, 19(3), 19-29.

Knijnik, J. (2018). The World Cup Chronicles: 31 days that rocked Brazil. Balgowlah Heights: Fair Play Publishing.

Knijnik, J; Hunter, J. and Vozzo, L. (2017). Aboriginal football in Australia: race relations and the socio-historical meanings of the 2014 Borroloola Tour to the Brazil World Cup. The Int. Journal of the History of Sport. 34 (15), 1635-1654 
Knijnik, J.; Luguetti, C. N. (2020). Social Justice narratives in academia: challenges, struggles and pleasures PETE educators face in understanding and enacting critical pedagogy in Brazil. Sport, Education and Society. https://doi.org/10.1080/13573322.2020.1732905

Knijnik, J. (2014). Playing for freedom: Sócrates, futebol-arte and democratic struggle in Brazil. Soccer \& Society, 15(5), 635-654.

Luguetti, C., \& Oliver, K. L. (2020). 'I became a teacher that respects the kids' voices': Challenges and facilitators pre-service teachers faced in learning an activist approach. Sport, Education and Society. doi: 10.1080/13573322.2019.1601620

Matamoros-Fernandez, A. (2017). Platformed racism: The mediation and circulation of an Australian race-based controversy on Twitter, Facebook and YouTube. Information, Communication \& Society, 20(6), 930-946.

Maynard, J. (2009). Football barriers: Aboriginal under-representation and disconnection from the "World Game". Soccer \& Society, 10(1), 39-56.

McInerney, P. (2009). Toward a critical pedagogy of engagement for alienated youth: insights from Freire and school-based research. Critical Studies in Education, 50(1), $23-35$.

Means, A. J. (2014). Educational commons and the new radical democratic imaginary. Critical Studies in Education, 55(2), 122-137.

Moriarty, J. (2000). Saltwater Fella: An inspiring true story of success against all odds. Melbourne: Viking Books.

Pang, B. (2018). Ethnographic Method. In P. Liampatting (Ed.), Handbook of research methods in Health Social Sciences (pp. 443-456). Springer.

Read, P. (1982). The Stolen Generations: The removal of Aboriginal children in New South Wales 1883 to 1969. Sydney, NSW: Ministry of Aboriginal Affairs Aboriginal Children's Research.

Rudd, K. (2008). Apology to Australia's Indigenous peoples. Canberra, ACT: House of Representatives, Parliament House, Canberra. Retrieved from http://www.unitcare.com.au/pdfs/Sorry Transcript.pdf

Shor, I., \& Freire, P. (1987). A pedagogy for liberation: Dialogues on transforming education. New York: Bergin and Garvey.

Silva, F. C. D., \& Sampaio, M. N. (2015). Cinquentenário das "40 horas de Angicos": Memória presente na educação de jovens e adultos. Revista Brasileira de Educação, 20, 925-947.

Streck, D. R. (2014). Ecos de Angicos: Temas freireanos e a pedagogia atual. Pro-Posições, 25, 83-101.

Stronach, M., Maxwell, H., \& Taylor, T. (2016). 'Sistas' and Aunties: Sport, physical activity, and Indigenous Australian women. Annals of Leisure Research, 19(1), 7-26.

Tatz, C. (1987). Obstacle race: Aborigines in sport. Kensington: University of New South Wales Press.

Torres, R.M. (2001). Os múltiplos Paulo Freire. In A.M. Araújo Freire (ed). A pedagogia da libertação em Paulo Freire (pp. 231-242). São Paulo: Editora UNESP. 
${ }^{1}$ João Guimarães Rosa was a Brazilian novelist who crafted a singular writing style creating neologisms in Portuguese inspired on the spoken language of the Brazilian country people. Author of Grande Sertão: Veredas (1956) translated as The Devil to Pay in the Backlands.

${ }^{2} \mathrm{He}$ never did play for the National Team as Australia was suspended from participating in FIFA tournaments in the early 1960s.

${ }^{3}$ The sugarcane workers are also known in Portuguese as boia-frias, which is a deprecatory term for 'cold food'. As these itinerant workers did not have a place to heat the meals that they brought from their homes or camps, they became known as the 'cold-food people' or boia-frias. Boia-fria is then an expression to name anyone who works in tough and low paid conditions, usually in rural areas.

${ }^{4}$ This research received ethics approval from the Western Sydney University Human Research Ethics Committee - H10877

${ }^{5}$ Former Socceroo football player and a famous sports TV commentator in Australia, also supporter of JMF programs.

${ }^{6}$ Respectively, Australian men's and women's national football teams. 